\title{
La Compañía Española de Minas del Rif (1907-1984)
}

\section{Ginés Sanmartin Solano}

Preámbulo

La COMPAÑIA ESPANOLA DE MINAS DEL RIF, S. A. (C.E.M.R.) nacida a principios de Siglo (año 1907), fue la más importante entre las pocas empresas que llegaron a ser realidad después de que fueran investigadas las muchisimas denuncias mineras que se habian hecho dentro del territorio marroqui, en la creencia (muy generalizada a principios de Siglo) de que todo el pais y en particular la Zona Norte, era un "emporio minero"...

Emporio, unas veces imaginativo y otras inventado: en el primer supuesto y a resuitas del natural ilusorio y crédulo que les es consustancial a muchos buscadores de minas, quienes, aunque con buena fe, en muchas ocasiones cometieron o indujeron a cometer grandes errores; en la segunda casuística, aventureros y embaucadores que condujeron al fracaso a mucha gente que con ilusión, habian arriesgado su dinero en unos supuestos negocios mineros que nunca llegarian a convertirse en realidad.

En aquella aventura de principios de Siglo participó mucha gente, unos a título personal y otros por cuenta de empresas, algunas de ellas importantes y bien reconocidas, entre las que cabe citar a título de ejemplo: W. Müller \& Co., holandesa; Marokko Mines Syndicat, Mannesmann Rif Co. y la Long Kompanie Scheschauen, alemanas; The Marocco Minerals Syndicate Limited y The Anglo Petroleum Syndicate, inglesas; otras mixtas como la, Sociedad The Anglo African Petroleum Syndicate Limited, Sociedad Madrileña Hispano-Marroqui, Asociación Syndicat Minier du Nort-Est du Maroc, etc., etc.

Es de destacar que las denuncias mineras que en principio se daban con más frecuencia en Guelaia y sus proximidades, a medida que se iba produciendo la penetración de España en su Zona de Protectorado, la ubicación de las supuestas riquezas se iban alejando más y más, de manera que siempre quedaban en lugares prácticamente inexplorados. Por los años veinte casi todas se situaban en el Rif y en terrenos muchos de c:llos controlados, más o menos directamente, por la familia Abdelkrim: Beni Urraiaguel, Beni Tuzin, Beni Ulichec, Tensaman, etc.

Es de destacar que las denuncias mineras que en principio se daban con más frecuencia en Guelaia y sus proximidades, a medida que se iba produciendo la penetración de España en su Zona de Protectorado, la ubicación de las supuestas riquezas se iban alejando más y más, de manera que siempre quedaban en lugares 
practicamente inexplorados. Por los años veinte casi todas se situaban en el Rif y en terrenos muchos de ellos controlados, más o menos directamente, por la familia Abdelkrim: Beni Urriaguel, Beni Tuzin, Beni Ulicheo, Tensaman, etc.

Capitulo aparte merecerian los Mannessmann y las empresas que ellos controlaban, quienes, ya desde el reinado de Muley Hafid y hasta la caida de Abdelkrim El Jattabi, desplegaron una gran actividad en todo el territorio de la Zona Norte y muy especialmente en la parte controlada por Abdelkrim.

Las denuncias fueron para toda clase de minerales: hierro, plomo, cobre, oro, yeso, petróleo, etc., etc.; las más de las veces las harian sin ni siquiera haber visitado el terreno y en otros casos, aún, habiéndolo visitado, sin haber tenido ocasión de hacer ni la más elemental exploración.

Algunos avispados, extranjeros o nativos, bien supieron aprovechar aquella época de inusitado interés por las minas. Con todo, fueron dos marroquies y cada uno de ellos en su época y en su región, quienes demostraron un mayor grado de sagacidad e intuición en cuanto a saberse aprovechar de la euforia minera reinante: Uno fue Bu Hamara en Guelaia y el otro, Abdelkrim El Jattabi en el Rif.

Lo tocante a las empresas mineras es otra cuestión.

Asi las cosas y pensando en las dificultades con que habria de tropezar cualquier persona que, ajena al tema, pudiera sentirse momentáneamente interesada por la mineria de Marruecos, es por lo que he creído que sería conveniente aportar algunos datos, tales que, en alguna medida, hicieran posible enmarcar el fenómeno minero de la época, en el contexto histórico de Marruecos de principios de siglo.

Con propósito expresado, nos hemos planteado el tema descomponiéndolo en los siguientes capitulos:

- Reseña sobre la Minería en Marruecos.

-Apuntes sobre la Historia de Marruecos - Epoca Moderna.

- Hechos curiosos relacionados con la minería.

-Anexo: Conteniendo Plano y Nota explicativa sobre los nombres empleados en el texto.

\section{Reseña sobre la minería en Marruecos}

A finales del siglo XIX todavía se ignoraba o cuando menos no era de conocimiento público la existencia de yacimientos mineros en la Región de Guelaia, zona que al igual que la mayor parte del territorio mogrebí, históricamente hablando, nunca se le había reconocido como país minero, sobre cuyo particular vamos a aportar algunos datos entresacados de una conferencia pronunciada por don Alfonso del Valle de Lersundi, Ingeniero y Geólogo español (Cámara de Comercio de Barcelona, año 1940).

Los textos consultados acerca de los antiguos pueblos colonizadores (Edad Antigua), fenicios, cartagineses y romanos que pasaron por estas regiones y que, principalmente, buscaban y explotaban las minas de oro, plata, plomo, cobre y estaño, no citan la existencia en esta comarca de estas riquezas mineras. 
Claro es que lo dicho (decia del Valle) no descarta que pueda existir algún yacimiento interesante, pero sí, que no era país reconocido como abundante en ellos, pues si así hubiera sido, habria ocurrido, por ejemplo, lo que en España, cuyas riquezas mineras son nombradas ya en los textos más antiguos, y conocidas y explotadas desde los tiempos prehistóricos.

En terrenos próximos a las minas de plomo del Monte Afra, en Beni-bu-Ifrur, se encontró un pequeño ídolo en bronce representando una Venus o Astarté que fue clasificada como de origen fenicio, cuyo hallazgo hizo sospechar que aquellas minas fueran conocidas por dicho pueblo que tuvo en sus proximidades la factoria Rusadir (la Melilla actual). En las labores interiores también se asegura que se habían encontrado candiles de procedencia romana, lo que hizo presumir que se hubieran efectuado trabajos en dicha época, pero la poca importancia de las escombreras y de los trabajos antiguos, no parece acusar la existencia de una explotación extensa ni continuada, y en cuanto a los restos de los candiles encontrados en aquellas labores mineras, posteriormente fueron clasificados como de tipo árabe, siendo presumible que la explotación principal fuera ejecutada por árabes 0 bereberes en tiempos mucho más modernos...

A juzgar por lo que se conoce de la historia de esta región durante la época de la dominación romana, la Mauritania Tingitana fue considerada siempre como colonia agricola o granero del Imperio, pero no minera; así es que el interés de Roma, a juzgar por los datos conocidos, consistía en asegurar las amplias vegas y llanuras fértiles del Sur, en donde estableció colonias agrícolas y para aislarlas y defenderlas de los ataques de las tribus montañesas de la costa Norte por una línea de puestos o fortines que impedian toda comunicación entre los habitantes del Rif $y$ las tribus del macizo hoy ocupado por los Beni-Ider, Beni Messaua y Yebel Habid. Esta cadena de fortines iba hacia el Sur, paralela a la costa, y en el interior, una vía que debía pasar por Taza y desembocar cerca de Fez, conducía de la Mauritania Cesárea a la Tingitana y aseguraba la comunicación con el centro de la ocupación imperial, Volubilis, en el doble macizo de Zerhun y el Tselfat, dominando las grandes llanuras de Beni-Hasán y Mequinez y completaba la separación del Rif de los otros territorios fértiles de la Tingitana. Examinado el Itinerario de Antonino se comprueba que así como en la Mauritania Cesárea existía una vía terrestre a lo largo de la costa, en la Tingitana esta via era exclusivamente maritima en toda la extensión montañosa que se extendía desde el Río Muluya hasta el Tamuda Oppidum (Tetuán).

Este hecho parece indicar que no se conocian en aquella época minas importantes en el Rif, pues, de encontrarse estas, también habrian sido ocupadas de una manera permanente, como lo fueron las regiones mineras de España, por aquel pueblo que fue eminentemente minero.

Tampoco en la Edac Media, se encontraba esta región citada como abundante en minas. Al final de la anterior o más bien ai comienzo de la Edad Moderna, se publicó una de las descripciones geográficas más exactas que se conocen de Marruecos, debida al converso granadino Juan León El Africano, y en ella se habla de la existencia de abundante mineral de hierro en la región de Uardana (Beni Said 
Oriental), en un lugar en el que los indigenas vivian casi exclusivamente de la explotación del mineral, del cual beneficiaban el hierro en forma de bolas (pellas) que cambiaban por mercancías a las tribus aledañas en los zocos. Aunque el nombre de Uardana lo lleva hoy un rio que vierte en el Kert, debía antes referirse a una región y las minas a que se refiere deben ser, las que se encuentran sobre el río Maaden que desemboca a Poniente de Punta Afrau y sobre el que existe un Morabo de Sidi Uardan. El mineral de estas minas, más dulce y fusible que el de Beni-bu Ifrur, se prestaba mejor que éste a la reducción en las antiguas forjas.

En la época en que escribía Alfonso del Valle se encontraron todavía las bolas de hierro a las que hacía referencia Juan León El Africano.

Durante la Edad Moderna, Marruecos no fue más conocido que en épocas anteriores (puede que aún menos) siendo por ello, que fuera considerado como un país nuevo cuando se aproximó el momento de la intervención por parte de las potencias europeas, pais éste que, por lo mucho que se ignoraba de él, cabía imaginar la posible existencia en su suelo de grandes riquezas mineras... $Y$ esto es lo que creían muchos a principios del siglo $\mathrm{XX}$ que es cuando comienza nuestra historia.

Apuntes sobre la Historia de Marruecos. Epoca Moderna

Es oportuno recordar que entrados ya en el siglo $\mathrm{XX}$, sólo quedaban como naciones soberanas en el Continente Africano:

La República de Liberia, estado independiente desde 1847, con el apoyo de las grandes potencias. Se había fundado agrupando a antiguos esclavos negros procedentes de los EE.UU.

Abisinia, que había resultado vencedora de Italia en 1896 y el Imperio de Marruecos.

Desgraciadamente, la suerte de Marruecos estaba ya echada desde que Inglaterra y Francia hubieron delimitado sus posiciones estratégicas en el Mediterráneo. En mayo de 1899, Francia e Inglaterra habían firmado un acuerdo por el que liquidaban el "Conflicto de Fachoda" y por el que Francia quedaba con las manos libres sobre Marruecos.

Entre 1900 y 1902, Francia establecía acuerdos con Italia y con España, y el 8 de abril de 1904 se firmaba el Tratado Anglo-Francés, conocido por "La Entente Cordiale", acuerdo por el que, por las dos Potencias, se reconocían unos derechos" de España en el Norte de Marruecos y que no fue otra cosa que la "utilización" de España por parte de Francia e Inglaterra, para evitar el desequilibrio que en el planteamiento estratégico de la región se habría producido en el caso de que cualquiera de las dos naciones hubiera dominado esta parte del Mediterráneo, dominio que ninguna de las dos estaba dispuesta a aceptar y que con la presencia de España quedaba resuelto, si bien que limitando el valor estratégico de las posiciones españolas, mediante ciertos condicionamientos que serian tenidos en cuenta llegado el momento de establecerse el Protectorado de España en la Zona Norte. 
El 7 de abril de 1906 se firmó el Acta de la Conferencia de Algeciras y el 30 de marzo de 1912, el Convenio de Protectorado de Francia con Marruecos.

Sólo pensar, en cuantos intereses habrian de entrar en juego y cuantas intrigas (políticas principalmente) en una época tan complicada como aquella, basta para comprender cuanta gente andaria buscando el medio o la ocasión de sacar provecho de la nueva situación de Marruecos que tan próxima se vislumbraba ya.

De otra parte y cuando el pais arrastraba y sufria las consecuencias de una serie de calamidades que habian comenzado a producirse desde poco después de mediados del siglo XIX (Guerra con España, sequías, epidemias...), en Europa había comenzado a despertarse un interés creciente por Marruecos. Interés que, de parte francesa, debió empezar a incubarse cuando la ocupación de Argelia (finalizada en 1847) y que por su proximidad a Europa debió ser como si se hubiera abierto una puerta a esta parte del Norte de Africa; de parte española, desde la Guerra con Marruecos (1859-60), contienda sobre la que se vertieron ríos de tinta en crónicas de corte romántico y de las que fueron buen ejemplo las escritas por Pedro Antonio de Alarcón.

Tuvo que ser desde las perspectivas citadas, desde las que numerosos viajeros emprendieron la aventura de explorar un territorio, que, aunque próximo geográficamente, había permanecido casi ignorado y prácticamente desconocido para los europeos, durante siglos.

Aquellos primeros viajeros: románticos y desinteresados, unos; y otros (los más sin duda), gente aventurera y a sueldo, posiblemente con misiones políticas secretas encomendadas por naciones europeas...

Unos y otros contribuyeron a construir la imagen fantástica y atractiva con la que se veía a Marruecos desde Europa al comenzar el siglo XX y, asi las cosas, cuando lo misterioso (por desconocido) ya habia calado en mucha gente, el descubrimiento en 1907 de los primeros yacimientos mineros (los de -Beni-bu-Ifrur) fue como una confirmación definitiva de que, lo que les atraía de Marruecos, no era sólo ilusión o fantasía, sino también una viva realidad. Aquellos descubrimientos contribuyeron a aumentar mucho más la ilusión y la ambición de muchos de los que seguian la evolución de los acontecimientos que se iban produciendo en Marruecos.

Pero, para que la época en que se iban a desarrollar los negocios mineros, fuera más dificil y complicada, todavia había de darse otra circunstancia perturbadora haciéndola más confusa y conflictiva. Nos referimos a la insurrección del Rogui, también conocido por Bu Hamara. Su nombre era Yilali Ben Mohammed el Yusfí ez Zerhoni, quien, alzado en armas contra el Sultán legitimo Muley Abdelaziz Ben Hassán (año 1902), después de vencer en algunas ocasiones a las fuerzas reales y de haber ocupado Taz:, vencido que fue por el ejército de Muley Abdelaziz (febrero de 1903) se retiró hasta Zeluán, Beni ku--Ifrur (11 de abril 1904), en Guelaia, en cuya alcazaba se instaló con su séquito y sus mehal-las, ejerciendo pleno dominio sobre una extensa parte del territorio.

La presencia de Bu Hamara en Zeluán condicionó la vida de un gran número de cabilas a las que exigió el pago de elevados tributos, creando al propio tiempo 
una aduana en la frontera con Melilla (Beni-Enzar, provincia de Nador).

Fue con Bu Hamara con quienes negociaron las Compañías Mineras la explotación de las primeras minas. Compañias de las que obtuvo elevadas cantidades de dinero por los permisos para llevar a cabo los trabajos de explotación y la construcción de los dos ferrocarriles mineros, uno para cada una de las dos primeras empresas que se iban a establecer en la región (Macizo montañoso de Beni-buIfrur): una fue la Compañía Española de Minas del Rif, S. A. que explotaria los hierros de los Montes Uixan y Axara y la otra la Compañia del Norte Africano, que tomaría a su cargo el yacimiento del Monte Afra.

La retirada de Bu Hamara de Zeluán se inició en diciembre de 1908.

Hechos curiosos relacionados con la minería

Algunos sucesos pintorescos acaecidos por entonces contribuian a aumentar la fantasía y la especulación sobre las supuestas riquezas mineras.

De entre ellos y como nota colorista citaremos los siguientes:

En 1847 el geólogo francés Coquad tuvo la misión de explotar los criaderos metálicos de la región de Tetuán y Tánger, debiendo de efectuar trabajos de investigación en un filón de mineral de cobre en el Valle de Kitsan? y en otro de antimonio en Beni Melal, pero las exploraciones no las pudo realizar ante la oposición de los indígenas que no veían con buenos ojos la presencia de extranjeros.

En 1882, el Conde Chavagnac compró a un rifeño preso en Mequinez, unos terrenos situados en el Yebel Hamman (Beni Urriaguel) que contenían oro, según decía.

Fletado un barco por el Conde con material de explotación se dirigió al lugar señalado, pero no pudo desembarcar ante la hostilidad de los indígenas. La tribu prohibió a los propietarios indigenas vender la mina y decidieron rechazar por las armas a los compradores.

Más tarde (octubre de 1904) en el diario El Africa Española y bajo el título "Historia de unas minas", se contaba: "Un hebreo acaba de vender a una casa de Orán ciertas "minas de oro" sitas en Bades, territorio de Beni Ytef, frente al Peñón de Vélez de la Gomera, y como no existen minas en aquel sitio, sospechamos que las enunciadas tengan relación con la aventura del Conde de Chavagnac...

El Conde desapareció sin haber visto ni de lejos sus supuestas propiedades, que cinco años más tarde revendió a otra persona, la cual a su vez la transmitió en 1903 por 80.000 francos al Conde de Canorgue, que es a quien se supone que han sido compradas ahora las minas de Yebel Hamman (Monte de las Palomas)".

El día 3 de septiembre, de 1909, el diario de Melilla El Telegrama del Rif, incluia una noticia sobre la riqueza del Rif, en la que se leía: "Es notorio que en el Yebel Hamman se extrae oro. La mayor riqueza se encuentra entre el Peñón de Vélez y Alhucemas"...?

Durante muchos años (hasta el Desembarco de Alhucemas) subsistiria la 
creencia de que existia oro en el Rif y más concretamente en el Monte de las Palomas, cosa muy comúnmente aceptada, aunque por algunos era cuestionada porfiando sobre que "lo que realmente habia en el Monte de las Palomas era plata, y no oro".

Muy poco después del Desembarco pudo comprobarse la falsedad de las supuestas riquezas mineras que venian diciendo que existian en el Rif, y por descartado que de oro, nada.

No obstante lo ocurrido en el Rif, es muy cierto que la creencia en la existencia de oro en Marruecos, es cosa asumida por gentes de diferentes épocas.

También el Monte Gurugú ha merecido la atención de los buscadores de oro. En el año 1932 se concedieron dos Permisos de Investigación para el reconocimiento de unos filones auríferos, cuya situación en el mapa está perfectamente definida. Los permisos fueron solicitados por una sociedad constituida en Melilla en el año 1932, titụlada "La Aurifera del Rif, S. A.".

Con posterioridad (años 1952-1954) y también en el Gurugú, por personas conocidas nuestras, se volvieron a realizar reconocimientos por los que se evidenciaron la existencia del precioso metal, pero...?

Y aún más, podría estar sucediendo en nuestros días que el interés por el oro del Gurugú, hubiera renacido.

Por último, creo que esta historia de los filones auriferos del Gurugú es algo que deberian tener presente los estudiosos de la Historia de Melilla, en lo que respecta al origen del nombre del Río de Oro.

Compañia Española de Minas del Rif, S. A. (C.E.M.R)

La C.E.M.R quedó constituida el día 21 de julio de 1908, mediante escritura pública establecida ante el Notario don Emilio Codecido Díaz.

El capital fundacional fue de 6.000 .000 de pesetas y los componentes del primer Consejo de Administración, fueron:

Presidente: Excmo. señor don Manuel Villanueva y Gómez.

Vicepresidente: Excmo. señor Duque de las Torres.

Consejero Secretario: don Jerónimo Roiz de la Parra.

Vocales: don Clemente Fernández y González, don Enrique Mac Pherson y Ramírez, don Alfonso del Valle de Lersundi, Excmo. señor don José Antonio Güell, Conde de Santa Coloma de Cervelló.

Antecesor de la C.E.M.R. fue el Sindicato Español de Minas del Rif, fundado el 7 de junio de 1907 y del que fueron promotores: don Clemente Fernández y González, don Enrique Mac Pherson y Ramírez, don Alfonso del Valle de Lersundi y la firma "G. A. Figueroa".

La creación de la C.E.M.R. fue precedida de un acuerdo con Bu Hamara (sabido es que al interfecto no le gustaba oír que le llamaran Rogui, pero tal era realmente, un "rogur").

Su verdadero nombre era Yilali Ben Mohammed el Yusfi ez Zerhoni, insurrecto que en aquellos tiempos controlaba por la fuerza la Región de Guelaia. 
La vida de Bu Hamara, contemplada hoy desde la perspectiva del tiempo, parece más la invención de un novelista que la historia de un personaje real. Ambicioso, inteligente y sin escrúpulos, inició una rebelión contra el Sultán legitimo Muley Abdelaziz (año 1902), tomando el nombre del Príncipe Muley Mohamed, hermano mayor de Abdelaziz, hijos ambos del Monarca difunto Muley Hassan... Pero esta es otra historia, que aunque muy interesante, no es para ser contada aqui, aunque sí era necesario decir algo sobre el tal Bu Hamara para comprender en qué medida fue necesario contar con él.

En cuanto a los dos apodos mencionados y por los que fue conocido, serán utilizados en adelante sin discriminación y empleándolos según convenga a la redacción.

La llegada de Bu Hamara a Zeluán tuvo lugar en abril de 1904.

El contrato con Bu Hamara fue firmado en la Alcazaba de Zeluán, el 26-12-1907, habiendo tenido lugar la ocupación material de la zona minera en los primeros días de enero de 1908, acto en el que participaron por parte del Sindicato, los señores Mac Pherson, Fernández González y del Valle.

Con anterioridad el prestigioso Sid Mohamed Ben Chel-lal, Caid de Beni-buIfrur había comunicado a todos los indígenas y jefes de cábilas la razón de tal ocupación y los beneficios que se esperaban de la explotación de las minas.

Lo más sustancial del acuerdo se resume así: Permiso por parte del falso Muley Mohamed para la explotación de los yacimientos de hierro de los Montes de Uixan y Axara (Beni-bu-Ifrur) y para la construcción de un Ferrocarril Minero de uns 24 kilómetros, vía de 1 metro de ancho, entre San Juan de las Minas y Beni-Enzar, frontera de Melilla. Permiso y protección al mismo tiempo, para quienes iban a participar en ambos trabajos.

Al acuerdo se llegó previa entrega por parte del Sindicato Español de Minas del Rif, de cuatrocientas mil pesetas (400.000) en metálico, exigiendo que fueran pagadas en "duros" españoles (moneda de plata de curso legal, de cinco pesetas, y 25 gramos de peso), cantidad que en peso equivalía a dos toneladas de plata acuñada y para cuyo transporte hasta Zeluán hubo que utilizar varias caballerias. También se reservaba una participación del $20 \%$ sobre los beneficios, a cuenta de los cuales y aún cuando la explotación estaba aún muy lejos de rendir fruto, exigió la cantidad de 250.000 pesetas anuales, pagaderas en dos mitades de 125.000 pesetas y cuyos dos primeros plazos correspondientes a 1908, tuvieron que ser adelantados. El 2.0 y último venció el 30 de septiembre de 1908.

Hasta que El Rogui llegara a pronunciarse en la concesión de los Permisos para la explotación de los yacimientos de Beni-bu-Ifrur, dos sociedades entre otras muchas rivalizaron y lucharon tratando de conseguir la parte que cada una de ellas pensaba que podría ser la más buena. Una fue la C.E.M.R., española en su totalidad y la obra, francesa de origen y con capital francés, la Compañía del Norte Africano; aquella que se inclinó por los yacimientos de los Montes de Uixan y Axara y la segunda que lo hizo por el Monte de Afra. También ésta tuvo que someterse a las exigencias del Rogui y creemos que no debieron diferir de las aplicadas a la C.E.M.R. 
Igualmente al Norte Africano proyectó su ferrocarril, pero de 0,60 metros de ancho y unos 28 kilómetros de longitud.

Naturalmente que la C.E.M.R. conocedora de la precariedad del Rogui, cuya aventura sabia que no podria prolongarse mucho tiempo y consciente de la necesidad de legalizar los Títulos Mineros, al propio tiempo que negoció con El Rogui para evitar la presencia material de otros competidores y que pudieran alegar derechos en su momento, también solicitó los oportunos títulos, del Sultán Muley Hafid, monarca legitimo, que era el que desde enero de 1908 ocupaba el Trono. Fue una gestión inteligente $y$ valiente que realizaron personalmente ante el Monarca, los señores Mac Pherson y Del Valle.

Una vez fundada la C.E.M.R., pronto comenzaron los trabajos en las minas y la construcción del ferrocarril pero, en octubre de 1908, la sublevación de las cábilas, contra El Rogui, que aprovecharon la ausencia de su ejército que se había desplazado hacia el Rif, supuso a la Empresa una pérdida importante de material y un retraso en los trabajos del Ferrocarril.

La marcha de Bu Hamara de Zeluán (4-12-1908) obligó a nuevas negociaciones con las cábilas más próximas a las mismas, pero cuando parecía que ya se había llegado a un acuerdo con sus representantes, dos días después de reanudados los trabajos (9-7-1909) se produjo una agresión por parte de los indígenas a los obreros que construian el ferrocarril a pocos kilómetros de Melilla ("2.a Caseta") de la que resultaron cuatro hombres muertos y otros tres gravemente heridos.

Reanudados finalmente los trabajos a finales de junio 1909, en junio de 1910 había quedado terminado el tramo de ferrocarril "Melilla-Limites" (Beni-Enzar) a San Juan de las Minas.

Conviene precisar que en ninguna de estas agresiones, al igual que también sucedería años después con Abdelkrim El Jattabi, los enfrentamientos nunca fueron con fuerzas del Majzen, sino que siempre fueron con gentes incontroladas.

Abierto al servicio el citado tramo de ferrocarril, a partir del 17 de agosto de 1911, para otros transportes, hasta el año 1914 no se pudo empezar a transportar mineral.

Aunque técnicamente en condiciones de iniciar los embarques de mineral y pese a que en su día la C.E.M.R. había solicitado de S. M. Muley Hafid el oportuno permiso para explotar las minas, de acuerdo con el Acta de Algeciras (7-4-1906), el comienzo de los embarques no podia tener lugar hasta que se hubiera cumplido lo previsto en el artículo 112. Entre tanto, los problemas alrededor de los minas cada día aumentaban más y más.

Por fin el año 1914 se publicaron dos Dahires con fecha 20 de enero:

Por uno se dictaba e. Reglamento de Minas y por otro un "Reglamento para la Resolución de los Litigios Mineros" (Boletín Oficial de la Zona n. 20 de 1914).

En dicho Reglamento se creaba una Comisión Arbitral compuesta por un Superárbitro designado por el Rey de Noruega y dos Arbitros: uno nombrado por S. A. Imperial el Jalifa y el otro por la nación de la que fuera súbdito el 
eventual recurrente.

A esta Comisión Arbitral, integrada por el Superárbitro noruego M. Gram, el español señor Altamira y el señor Aguirre por el Majzen, hubo de someterse la C.E.M.R. en defensa de sus derechos.

Al estallar la Guerra europea en 1914, la "Comissión Arbitrale des Litiges Minieres, au Maroc", en vista de la situación creada y a demanda de la C.E.M.R., concede a ésta un Permiso de Explotación Provisional, en 27 de julio de 1914.

Al amparo de este Permiso la Compañia hizo su primera exportación de mineral el 21 de noviembre de 1914 en el vapor "Marzo" embarcando 1.800 toneladas con destino a Nweport (Inglaterra).

Habian transcurrido ya más de siete años desde que se fundara el Sindicato Español de Minas del Rif, con un capital inicial de dos millones de pesetas (2.000.000), pero que ya en 1914 había obligado a desembolsos del orden de los diez millones, cantidad que era a la que se elevaba el Capital Social de la C.E.M.R. en 31 de diciembre de 1914.

Durante el mismo periodo de tiempo se fueron incorporando a la Compañia algunos grupos financieros, entre los que son de destacar los representados, uno por don Alejandro de Gandarias y Durañoña (que pasó a presidir el Consejo de Administración ya en 1909) y otro por el Conde de Zubiría.

Terminaba la guerra de 1914, vuelve a reunirse la Comisión Arbitral de París y se sustancia el litigio planteado por otros aspirantes extranjeros que habian intentado disputar los derechos de la C.E.M.R., dictando la Comisión su sentencia de 13 de marzo de 1920, por la que se le concedía a la Compañía Española de Minas del Rif los oportunos Permisos de Explotación, quedando desde entonces reconocidos sus legitimos derechos.

Dicha sentencia de la Comisión Arbitral fue confirmada por Dahir de 26 de octubre de 1921, publicada en el Boletín Oficial de la Zona de Protectorado de 1012-1921.

Es a partir de la Sentencia de 13 de marzo de 1920, cuando la C.E.M.R. se plantea la necesidad de acomodar las inversiones dinerarias a lo que técnicamente tenía ya previsto la empresa para conseguir que los embarques llegarán a alcanzar tonelajes acordes con la importancia de los yacimientos de Uixan y Axara.

El plan abarcaba, fundamentalmente: aumento de la capacidad de arranque en las minas, incluidas las oportunas instalaciones de tratamiento de los minerales; adecuación del ferrocarril mediante la incorporación de material moderno (vagones nuevos y algunas locomotoras); la construcción de una Central Termoeléctrica con capacidad para atender todas las necesidades de la Empresa (incluídas las explotaciones mineras, el futuro embarcadero, etc.) y un Cargadero de Minerales, estas dos instalaciones en el Puerto de Melilla.

En cuanto a la ubicación del Cargadero, aparte de que la C.E.M.R. fuese una sociedad española, es justo reconocer que por entonces y aún mucho después, no se podía concebir otro lugar para su ubicación que en el Puerto de Melilla.

Fue en el año 1920 cuando el capital social fue elevado a ochenta millones de pesetas $(80.000 .000)$. 
El Cargadero de Minerales quedó terminado en el 1925 y en normal funcionamiento desde el año 1926. Fue una instalación entre las mejores de su época, realizada a base de hormigón armado y cuyas características técnicas eran: muelles con capacidad de ataque para buques de hasta 160 metros de eslora, 20 metros de manga, 10 metros sobre el nivel del mar y 8,50 metros de calado y capacidad real de carga de 1.000 toneladas por hora a partir de una capacidad técnica de 2.000 toneladas hora, que era el ritmo de carga.

La capacidad de almacenamiento eran 100/110.000 toneladas, con posibilidad de carga inmediata de 50/60.000 toneladas.

Fue una instalación bien concebida y perfectamente realizada que respondió por completo a las necesidades de las explotaciones mineras.

Durante los años 1927, 28 y 29 embarcó un promedio de 800.000 toneladas/ año, habiendo superado el millón de toneladas en varias ocasiones y por primera vez los años 1937 y 1938.

En el año 1931 entró en funcionamiento la Nueva Planta de Quebrantado, Estrio y Concentración en el Uixan con capacidad de tratamiento de 750 toneladas/hora. Obra importante de ingeniería construida en la ladera Este del $\mathbf{M}$. Uixan, entre las cotas de nivel, 316 y 220 metros y en la que se empleó una gran cantidad de hormigón armado.

La entrada en servicio de la nueva planta hizo posible una mayor recuperación del mineral, al mismo tiempo que permitía obtener los calibres que el mercado exigia.

Durante el mismo periodo de tiempo, años veinte al treinta, se construyeron o se perfeccionaron otras instalaciones auxiliares tales como Hornos de Desulfuración para la eliminación del azufre por tostación y un Lavadero de Minerales en el Atalayón para el desenlodado de los minerales llamados "chirteras".

La modernización de la explotación minera había precedido a todo lo enunciado, formando parte del plan de conjunto elaborado muchos años antes.

Los frentes de cantera se establecieron entre 20 y 30 metros de altura y se incorporaron máquinas barrenadoras eléctricas para la perforación de grandes barrenos ( 20 a 35 metros de profundidad y diámetro mínimo de $200 \mathrm{~mm}$.) para el arranque por "grandes voladuras". Algunas llegaron a las 350.000 toneladas de arranque con una carga de 30.000 kilos de explosivos, si bien, las más frecuentes fueron entre 80.000 y 160.000 toneladas.

Una quebrantadora "Traylor" de trompo vertical con entrada de cuarenta y dos pulgadas, accionada por un motor de $300 \mathrm{HP}$., era el elemento principal de la Nueva Planta; por el que se hacia posible la descarga de los grandes bloques (hasta una yarda cúbica) de mineral procedente de las "voladuras".

Pero dado que serír. excesivo entrar en la descripción técnica de las distintas secciones de la mina, para quienes pudieran sentirse interesados en ello, les remitimos a la revista "Mines et Geologie", de la Direction des Mines et Geologie, número 14, 4eme; deuxieme trimestre 1961, dedicado a la Provincia de Nador.

Dejamos sin desarrollar las relaciones que existieron entre la Compañía del Norte Africano y la C.E.M.R. y el por qué se llegó a la compra por parte de esta 
última, del ferrocarril de vía de 0,60 y de todas las instalaciones y dependencias que poseia la Norte Africano con excepción de las propias Minas de Afra (año 1918) por el mundo tiempo que ello nos llevaria a la par que nos alejaria del eje principal de este trabajo.

Tampoco entraremos en lo referente a la explotación por parte de la C.E.M.R. de los ferrocarriles, otros que para el transporte de mineral (Transporte de viajeros, de mercancías, etc., etc.).

Sí tenemos que mencionar la compra en 1946 de la S.A. Minera SETOLAZAR (S.A.M.S.) por parte de la C.E.M.R, aunque fue aquella una sociedad que, (hasta el mismo momento de la "reprise" por parte del Gobierno Marroqui), hubiera seguido funcionando como entidad autónoma, entre otros motivos, también por razones técnicas.

La S.A.M.S. habia sido fundada el 9 de junio de 1913 agrupando un grupo de minas existente entre los perímetros mineros de la Norte Africano y de la C.E.M.R.

Período de prueba para la C.E.M.R. fueron los años 1931 a 1933 en los que la profunda crisis de mercado coincidió con los grandes desembolsos que había venido efectuando la empresa desde hacia varios años. Las ventas quedaron reducidas a $488.205,142.307$ y 389.613 toneladas/año, respectivamente.

Aquella crisis obligó a reducir drásticamente los gastos, originando el despido masivo del personal; de todo lo cual se derivaron grandes problemas.

Terminado el Protectorado y restablecida la Soberanía de Marruecos, en cumplimiento del acuerdo concertado entre el Gobierno de Marruecos y la Compañía Española de Minas del Rif, según el Protocolo firmado por las dos partes el 15 de abril de 1959 y acuerdo de la Junta General de Accionistas celebrada el 20 de junio del mismo año, la C.E.M.R concedió una participación al Estado de Marruecos de 31.381.800 pesetas, cantidad que sumada al capital social de entonces, que era de 86.300.000 pesetas, pasó a ser 117.681 .800 pesetas lo que supuso una participación porcentual del Estado marroquí en la C.E.M.R. equivalente al $26,67 \%$ del nuevo capital social.

Desde 1959 a 1967, previa creación de un Departamento Geológico y una Oficina de Estudios, la C.E.M.R. (por sí sola o con la colaboración del B.R.P.M.) llevó a cabo una exhaustiva campaña de investigación en todos los Permisos Mineros de los que era titular (e incluso sobre otros muchos terrenos) y muy especialmente sobre las Concesiones números 154, 155 y 156 (esta última correspondiente a S.A.M.S.).

Se hicieron amplios y detallados estudios geológicos seguidos de una costosa campaña de sondeos, en cuyos trabajos participaron, además de los propios geólogos e ingenieros de la C.E.M.R. y S.A.M.S., el B.R.P.M. y alguna otra empresa especializada contratada para tal fin, entre ellas la "Compañía de Prospección Geofisica, S.A." (GEOPROSCO) a la que se le encargó la prospección geofisica de todos los terrenos que en opinión de los geólogos pudieran parecer interesantes.

Resultado de la investigación realizada fue la localización de nuevas masas de mineral y un mejor conocimiento del conjunto de las reservas, tanto en cantidad 
como en calidad.

Con todo ello se hizo evidente que los minerales en otro tiempo explotados en los criaderos de Beni-bu-Ifrur, de excelente calidad y situados entre los más cotizados del mercado, habian experimentado un empobrecimiento progresivo, precisamente en un momento en que en el mercado se exigian minerales más puros, asi, pronto se comprendió que la posibilidad de comercializar dichos minerales precisaba de un cambio radical en la forma de explotar el yacimiento y fundamentalmente en los tratamientos a que debían ser sometidos.

Las reservas estaban constituidas por los restos, no oxidados, de los criadores de Uixan, Axara y SETOLAZAR y por la masa de mineral de Imnassen, descubierta en las últimas campanas de investigación a una profundidad aproximada de 100 metros.

Pronto se dedujo que, al ser minerales con un conjunto en azufre relativamente alto y ser el componente principal magnetita, el tratamiento lógico sería moler hasta liberar la parte más rica en azufre y concentrar después el producto...

Así las cosas y considerando que la pureza del producto estaría en función del grado de molienda, se llegó a la conclusión de la necesidad de pelletizar.

Circunstancias que no vienen al caso analizar, desembocaron en la "reprise" de las minas por parte del Estado de Marruecos, según acuerdo adoptado por el Gobierno Marroquí en 31 de marzo de 1967, en relación con lo cual y para hacerse cargo de las explotaciones que tenía a su cargo la C.E.M.R y la S.A.M.S., fue creada la Societé "d'Eploitation des Mines du Rif" (SEFERIF), Sociedad que tomó a su cargo la explotación de las minas en $1 .^{\circ}$ de febrero de 1968.

Entre tanto la C.E.M.R. en la Junta General Extraordinaria de Accionistas celebrada el 28 de junio de 1967 acordó liquidar la Sociedad, si bien y para facilitar los embarques de la SEFERIF, fue necesario crear una nueva Compañía que se encargaría del transporte hasta el Puerto de Melilla de los minerales de SEFERIF, para su embarque por el Cargadero de Minas del Rif.

La nueva Sociedad se llamó "Embarques y Transportes del Rif, S. A." (E.T.S.A.) y quedó constituida con fecha 6 de julio de 1967, la cual tomó a su cargo las Concesiones Administrativas del Ministerio de Obras Públicas de España de las que era titular la C.E.M.R., en Melilla, aportando al mismo tiempo junto con las instalaciones y dependencias que poseía en Melilla, la parte de capital necesario para alcanzar el mismo Capital Social que tenía la C.E.M.R. al acordar su disolución (117.681.800 pesetas) que fue suscrito en su totalidad por los antiguos accionistas de la C.E.M.R, conservando el Estado Marroquí en la nueva Sociedad (E.T.S.A), la misma participación del $26,67 \%$ que tenía en la anterior.

El transporte de los minerales de SEFERIF con el ferrocarril de E.T.S.A. finalizó el 30 de agosto de 1972, habiéndose efectuado el último embarque de mineral por el Cargadero de Melilla, el día 3 de julio de 1980: 6.700 toneladas para "Phillips Brothers" (Inglaterra).

Anulado en su dia el ferrocarril de E.T.S.A. y suspendidos ya definitivamente los embarques de mineral de SEFERIF y sin otra posibilidad de utilizar el Cargadero por parte de E.T.S.A, nada le quedaba por hacer y menos aún, cuando, preci- 
samente por dejar de utilizarse como tal, el Cargadero pasaba a ser propiedad del Estado español.

Así las cosas, en sesión extraordinaria celebrada el 16 de octubre de 1984, la Junta General de Accionistas de E.T.S.A., acordó la liquidación de la Sociedad.

Con el citado acuerdo se ponia fin a una Empresa (la C.E.M.R) estrechamente vinculada a la Historia Móderna de Marruecos y de España y que (con abstracción de consideraciones de orden político que no es este el momento de comentar, etc.), es evidente que contribuyó en buena medida al desarrollo industrial y mercantil de Melilla en el siglo XX y también a la formación profesional y humana de muchos españoles y marroquies. En la provincia de Nador la demanda de trabajo de las minas alcanzó cotas de empleo muy importantes y en Melilla, aunque en menor cuantía, el personal ocupado tuvo una gran incidencia en el ámbito laboral local, debido a la especialización y cualificación de la mano de obra que se precisaba para la atención y funcionamiento de las diferentes instalaciones aquí ubicadas, a saber; talleres mecánicos y depósitos de locomotoras en el recinto de "Hipódromo II" (sobre una parcela de $38.000 \mathrm{~m}^{2}$, unos $4.000 \mathrm{~m}^{2}$ de naves para talleres, $y$ aproximadamente otros $4.000 \mathrm{~m}^{2}$ construidos, destinados a oficinas, almacenes, garages, etc.); estación de ferrocarril y parque de material rodante en "Hipódromo I" (unos $30.000 \mathrm{~m}^{2}$ ); Vías de F. C. de 1,00 metro de ancho, hasta el puerto; central Eléctrica (vapor y diesel) con una potencia instalada de $6.300 \mathrm{Kw}$.; cargadero de minerales, cuya actividad colocada al Puerto de Melilla en un lugar destacado entre los demás puertos españoles, etc.

Así y aunque es justo reconocer que también existieron otras empresas mineras que contribuyeron al desarrollo de Melilla, Minera Setolazar, Minas de Afra, etc., también es cierto que fue la Compañía Española de Minas del Rif, la que contribuyó en mayor medida, y que su nombre y prestigio comercial estuvieron siempre unidos al de esta ciudad, a cuyo puerto, y durante más de medio siglo, atracaron miles de barcos en épocas en las que el Cargadero de la C.E.M.R. gozaba fama de ser una instalación modélica en su género.

No soy capaz de calibrar el interés que puede tener para el público lo referente a las antiguas empresas mineras, pero de lo que si estoy convencido es de que la Historia de España en el siglo XX (y muy en particular la de Melilla) no estaría completa si no se incluyera lo relacionado con las mismas, basado en lo cual y al propio tiempo que para recordar un pasado irrepetible para Melilla, brindo las presentes líneas a quienes puedan sentirse interesados por el tema, como sugerencia para un estudio en profundidad de la problemática minera y de su repercusión politica y económica, no sólo en la región en la que se encuentra enmarcada Melilla geográficamente, sino en el contexto general de las relaciones hispano-marroquies, para finalmente analizar el porqué de la presencia de España en Marruecos y la medida en que los negocios mineros pudieron influir en dicha presencia, estudio que 
también habria de abarcar la repercusión que tuvieron en la peninsula, los problemas surgidos desde que comenzó la penetración de España en Marruecos.

1

Completar los datos reseñados en la presente memoria en cuanto se refiere a la C.E.M.R. y realizar el estudio político y económico de la época, sería una interesante e importante aportación a la Historia. 


\section{ANEXOS}

Plano de Guelaia:

Notas explicativas sobre algunos nombres citados en el texto 


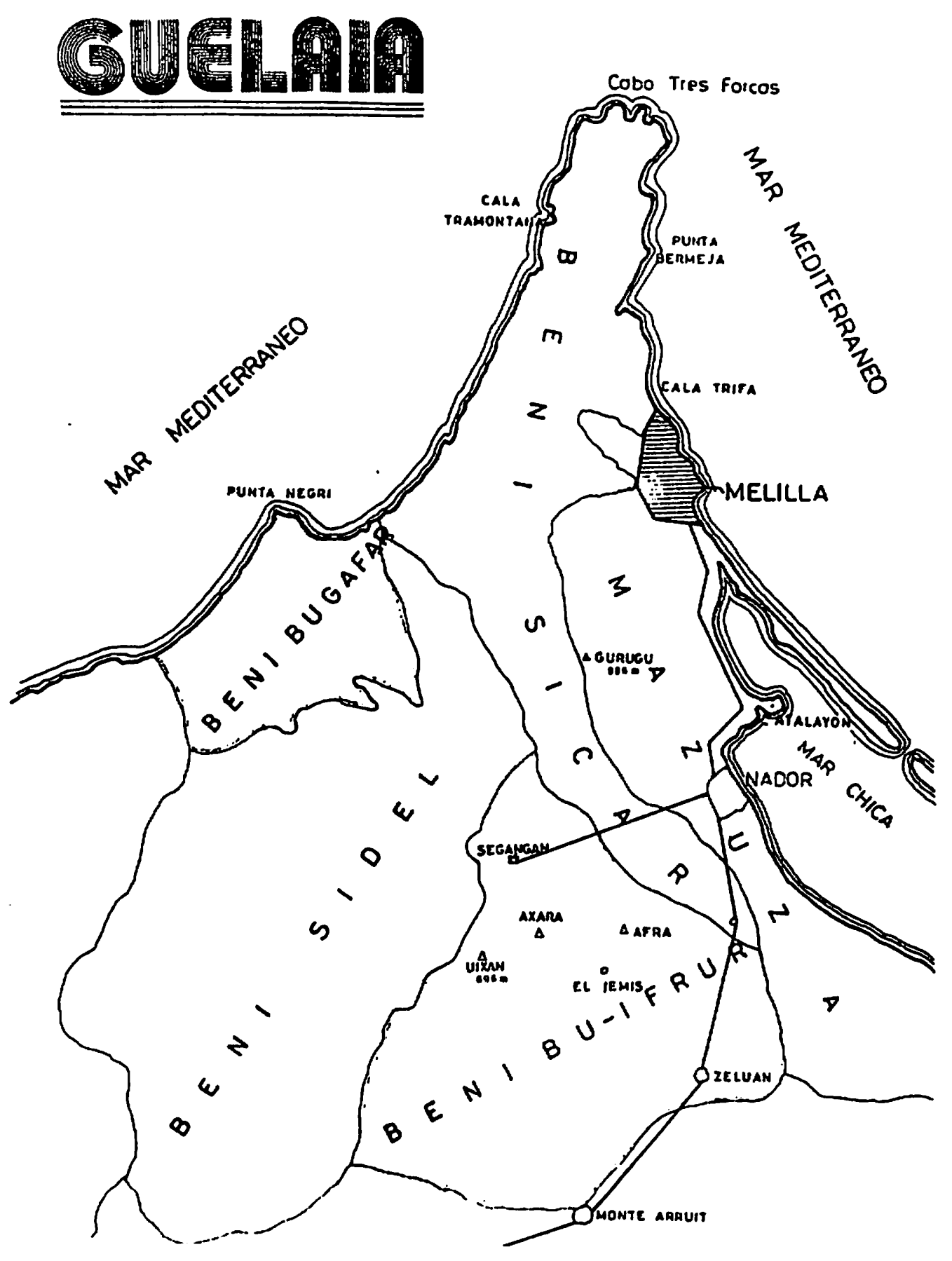


Notas explicativas sobre algunos nombres citados en el texto

Guelaia.-Tambiẻn se escribe: Guelaya, Quelaia o Kelaia. Es el territorio de la Peninsula de Tres Forcas.

Algunos dicen que Guelaia significa "Castillito" y otros "Lugar de castillos", análogo a nuestra "Castilla" y puede proceder de las fortalezas que, como Taxuda, Melilla y Cazaza, han existido desde tiempo antiguo en este territorio. (Boletín del Instituto Geológico de España, Tomo XVIII-1917.)

La región de Guelaia comprende cinco cabilas: Beni-Bugafar, Mazuza, Beni Buifrur y Beni Sidel.

Monte Uixan.-(Yebel Uixan). Se traduce por "Monte de Lobos" o con mayor propiedad por "Monte de Chacales", ya que lo que realmente hemos visto con frecuencia y en cantidad por aquellos parajes, son chacales.

Con el tiempo surgió un poblado minero europeo con el mismo nombre, más próximo a la explotación minera y mucho más importante que el de San Juan, entre los fuertes de San Jerónimo, San Enrique y Nuestra Señora del Carmen, junto al poblado musulmán de Sidi-bu-Sbar.

Axara.-(Yebel Axara) "Monte de Piedra" o "Monte de las Piedras". El mineral de hierro aparecia fragmentado y en grandes piedras.

De este yacimiento se extrajo durante mucho tiempo el imán en estado natural, el "óxido ferroso-férrico $\left(\mathrm{Fe}_{3} \mathrm{O}_{4}\right)$ ".

Setolazar.-Es el nombre de la "Sociedad Anónima Minera Setolazar" y el del poblado minero construido por dicha empresa al margen del camino de Segangan a Zeluán, entre Axara y El Jemis.

El nombre se formó tomando las primeras silabas de los apellidos de los fundadores: Francisco Setuain San Emeterio, Juan Olavarriaga Eguilor y Félix Ortiz de Zárate Lejarazu.

\section{“Set-Ola-Zar"}

San Juan de las Minas.-Poblado minero de la Compañia Española de Minas del Rif, construido en la cabecera del ferrocaril via de $1,00 \mathrm{~m}$., en las proximidades de Segangan y a orillas del camino que unía este poblado con Zeluán, pasando por Setolazar y por El Jemis.

San Juan fue el primer poblado europeo construido en la región.

Alcazaba.-Según el diccionario, la alcazaba es una fortaleza, pero tanto la de Zeluán como las otras que hemos visto en Marruecos, son sólo unos recintos cerrados con muros de no mucha altura, construidos con barro mezclado con paja o estiercol.

La Alcazaba de Zeluán, que fue construída en tiempos de Muley Ismail (Siglo XVII de la Era Cristiana), en planta, es un polígono irregular de cuatro lados (200, 
190,228 y 129 metros) con una superficie aproximada de $17.700 \mathrm{~m}^{2}$. (Datos tomados de "El Rogui", E. Maldonado-Año 1949.)

B.R.P.M.- "Bureau de Recherches et de Participations Minieres", Organismo estatal encuadrado en el "Ministerio de l'Energie et des Mines", de Marruecos.

Por medio de este organismo, el Estado Marroquí está representado en las sociedades en las que tiene alguna participación (cual sucedia con la C.E.M.R.), como también se sirve de él para controlar técnicamente a muchas otras empresas, mediante la información que va obteniendo de las investigaciones que se van realizando.

Seferif.- “Société d'Exploitation des Mines du Rif", empresa encuadrada en el B.R.P.M., sucesora de la C.E.M.R. en la explotación de las concesiones mineras de Uixan, Axara y Setolazar.

\section{Geoprosco.- “Compañía de Prospección Geofisica, S. A."}

Protectorado.-Al hablar de protectorado debemos recordar que el Convenio de Protectorado fue firmado entre Francia y Marruecos el 30 de marzo de 1912, firmándose el 27 de noviembre del mismo año, el Convenio entre España y Francia, en el que se fijaba la situación de ambas Potencias en Marruecos.

Rohgui.-En verdad debe decirse Rogui y procede del nombre de un insurrecto llamado Chelil er Rogui, que en 1862 murió al intentar derrocar al Sultán Sidi Mohamed.

Desde entonces que, "Rogui, es el nombre que se da en Marruecos a todo agitador que aspira a derrocar por medio de una revolución al Sultán reinante" (Diccionario de la Lengua Española).

Más adelante se verá, porqué toleraba que le llamarán Bu Hamara y por qué reaccionaba con dureza, incluso con crueldad, contra quienes venía en conocimiento de que se habian referido a él, llamándole Rohgui.

Las autoridades españolas y la prensa (sobre todo en Melilla), solían referirse a él llamándole "El Pretendiente".

También fue conocido por "El Señor del Rif".

Bu Hamara.-Se puede traducir por "El de la burra" "El tío de la burra" o "El padre de la burra".

Apodo el de Bu Hanıara, que el propio Yilali Ben Mohamed el Yusfi ez Zerhoni (el pseudo Muley Mohamed Ben Hasán) debió propiciar para que así le llamaran y ello por lo del isignificado religioso? que podia tener la burra (o la mula, que, para el caso da una como otra).

Esta versión sobre Bu Hamara que relatamos a continuación, es a título personal y partiendo de que el sujeto emprendió una aventura, apareciendo en el zoco 
diciendo que era "el heredero legitimo, al que le había sido usurpado el trono de su padre el difunto Muley Hasan..."

La aparición la hizo a lomos de una burra y, acompañado siempre de ella al comienzo, alentó y provocó la subversión contra el que, él decia que era su hermano, el Sultán Muley Abdelazis, diciendo de él que, además de usurparle el Trono, se habia echado en manos de los infieles extranjeros.

Con el argumento expuesto y nombrándose a sí mismo "Defensor de la Fe", pronto reunió un ejército con el que hizo frente, primero a Muley Abdelazis (al que venció en diferentes ocasiones) y después a Muley Hafid.

Muley Hafid ocupó el Trono de Marruecos (1908-1912), al derrocar a su hermano Abdelazis.

Fue una época en la que estuvieron en disputa por el Trono, el falso Muley Mohamed (Bu Hamara) y los hijos de Muley Hasan, Abdelazis y Hafid, parte ésta de la Historia de Marruecos, que fue recogida por Enrique Arqués, en su libro titulado "Tres Sultanes a la Porfia de un Reino" (Año 1942).

Por fin Bu Hamara fue vencido y hecho prisionero por el ejército de Muley Hafid (14-8-1909); metido en una jaula fue llevado públicamente hasta Fez, exhibiéndose a la gente que le insultaba, escupia y apedreaba.

Condenado a ser comido por los leones, era tal el estado en que había quedado que las fieras no lo quisieron, por lo que tuvo que ser finalmente decapitado.

En cuanto a la burra y su significado, en principio puede establecerse la diferencia; entre el hombre a lomos de una burra, ofreciendo una "imagen de mansedumbre y de hombre de paz" (acorde también con la del hombre piadoso), y la que da sobre un caballo que (aunque no siempre), bien puede dar la "imagen de la agresividad o de la guerra"...

$\mathrm{Y}$ puesto que con Bu Hamara estamos y habida cuenta del importante papel que dicho personaje jugó en la iniciación de los negocios mineros, como cosa curiosa y para abundar en apoyo de mi versión sobre el apodo, citaremos a continuación, y por último, algunas de las veces que la burra es citada en textos religiosos:

La Burra de Balam, en la Biblia; en la Entrada de Jesucristo en Jerusalén, el Domingo de Ramos; la entrada en el Paraíso del Profeta Mahoma, a lomos de la Burra de Burac; etc.

La Burra de Burac aparece en dibujos turcos antiguos ("Mahoma y el Islam", de Umberto Rizzitano), tiene cuerpo de animal y cabeza de mujer coronada y va precedida del Angel Gabriel. 